\title{
PERCEPÇÃO DOS TRABALHADORES DE SOLDAGEM EM RELAÇÃO À EXPOSIÇÃO AOS RISCOS DE ACIDENTES NO LOCAL DE TRABALHO
}

Thalyta Moraes Andrade Dias*, Giovana Fernandes Araújo**

\footnotetext{
Autora correspondente - Thalyta Moraes Andrade Dias: thally_moraes@hotmail.com

* Graduanda do curso de Enfermagem da Faculdade Independente do Nordeste

** Enfermeira, Mestre em Meio Ambiente e Sustentabilidade. Especialista em Enfermagem do Trabalho e Saúde da Família. Professora do curso de Enfermagem da Faculdade Independente do Nordeste
}

\section{Resumo}

O presente estudo objetivou identificar a percepção dos trabalhadores de soldagem em relação à exposição aos riscos de acidentes no local de trabalho e as medidas de prevenção. Para tanto, foi realizado um estudo qualitativo, baseado em entrevistas gravadas com roteiro semi-estruturado, com nove (9) colaboradores que trabalham diretamente expostos à solda. $O$ estudo revelou que os trabalhadores detêm pouco conhecimento em relação aos riscos que estão expostos além da proteção individual ser inadequada. Tal fato requer, da empresa, uma maior atenção no que diz respeito à fiscalização quanto ao uso dos Equipamentos de Proteção Individual (EPI) e programas direcionados a melhoria sobre o conhecimento da segurança ocupacional.

Palavras-chave: Risco ocupacional; Saúde do Trabalhador; Soldagem.

\section{WELDING WORKERS' PERCEPTIONS ON EXPOSURE TO ACCIDENT HAZARD IN THE WORK ENVIROMENT}

\begin{abstract}
This study aimed to identify the perceptions of workers welding in relation to exposure to the risks of accidents at work and prevention measures. Thus, a qualitative study, based on taped interviews with semi-structured, with nine (9) employees who work directly exposed to welding was performed. The study revealed that workers hold little knowledge about the risks they are exposed beyond the individual protection
\end{abstract}


is inadequate. This fact requires, the company increased attention with regard tosupervision regarding the use of Personal Protective Equipment ( PPE) and programs aimed at improving the knowledge on occupational safety. Keywords: Occupational risk; Occupational Health; Welding.

\section{INTRODUÇÃO}

As doenças ocupacionais constituem-se um problema de saúde pública, uma vez que estudos crescentes mostraram que as mesmas trazem prejuízos relevantes à saúde do trabalhador. As formas de adoecimento de trabalhadores da indústria guardam relação com as diferentes modalidades de gestão do trabalho e da produção. As exigências sobre as capacidades cognitivas e psíquicas e sobre o corpo podem ser expressas como doenças relacionadas ao trabalho. ${ }^{(1)}$

A função de soldador destaca-se como uma das principais atividades que podem gerar doenças ocupacionais. A atividade de soldagem é considerada como sendo de grande risco ao profissional que a executa, podendo comprometer a saúde. Agentes físicos, químicos, biológicos, ergonômicos e de acidente estão sempre presentesem seu ambiente de trabalho. ${ }^{(2)}$

O calor, as radiações ionizantes e não ionizantes são os principais riscos físicos que o soldador está exposto. Já os riscos químicos que o trabalhador pode encontrar no ambiente de trabaIho são os fumos de solda e o esmerilhamento do metal da tornearia mecânica. O risco ergonômico também é notável no setor da solda, principalmente devido ao peso dos equipamentos que, muitas vezes, são transportados de maneira inadequada. ${ }^{(3)}$

O processo de soldagem é utilizado de diferentes maneiras industriais e tem fundamental importância no ramo da fabricação no setor de metal mecânico. (4) Devido o crescimento dos setores siderúrgico, metalúrgico e petroquímico, a utilização de técnicas de soldagem teve um aumento consi- derável. Consequentemente o número de demanda de profissionais qualificados aumentou (soldadores, técnicos, inspetores e engenheiros), assim como o conhecimento técnico, fiscalização e exigência por um padrão de qualidade elevado. ${ }^{(1)}$

Segundo Goldman, (5) com base nas Comunicação de Acidente ao Trabalho (CATs) constatou-se que o principal tipo de acidente que ocorre com o soldador é o impacto sofrido (40\%), seguido de doença profissional (13,33\%), motivada por LER e ruído e por último a prensagem (6,67\%). Estes dados vêm contra o que se espera que aconteça com o soldador. Alguns fatores podem influenciar na qualidade do trabalho do soldador e na sua atenção. Sua principal preocupação é com a visão e zona respiratória devido aos fumos de soldagem. Estes podem causar cefaleia, lipotímia e estresse, aumentando assim o risco de acidente durante a execução de suas atividades. Outro problema associado a função do soldador é o estresse postural. Um soldador tem basicamente umas seis posições diferentes de trabalho, basicamente estáticas, com movimentos curtos, onde ele pode passar até meia hora em uma determinada posição até o dia inteiro. ${ }^{(6)}$

O controle dos riscos e das doenças ocupacionais advém da junção do trabalho simultâneo entre a engenharia e a medicina. Para que isso ocorra é necessário o reconhecimento dos perigos, dos Equipamentos de Proteção Individual (EPI) e Equipamentos de Proteção Coletiva (EPC) e das doenças ocupacionais. Portanto, os profissionais responsáveis pelo controle dos riscos ocupacionais 
devem estar cientes das funções que serão desenvolvidas em cada setor de uma empresa com o intuito de promover a segurança dos profissionais de cada área.

O Ministério do Trabalho, por meio da portaria 3.214, aprovou as Normas Regulamentadoras (NR's), a partir de 1978. As empresas devem manter de acordo com as NR's do Ministério do Trabalho e Emprego (MTE), um Programa de Prevenção de Riscos Ambientais (PPRA - na portaria/MTb n 19/1998, NR9), que considera os diversos riscos que podem existir no trabalho, que devem ser quantificados e identificados, assim a partir dessas informações é possível direcionar ações do Programa de Controle Médico de Saúde Ocupacional (PCMSO - NR7) que irá proceder para as avaliações de saúde dos trabalhadores. ${ }^{(7)}$

O interesse em realizar esta pesquisa surgiu a partir da vivência em um Serviço de Segurança e Saúde do Trabalhador onde são atendidos profissionais da área de soldagem que estão expostos a fatores de risco, chamando a atenção para este tipo de ocupação. Além disso, os estudos sobre o tema podem contribuir para o meio acadêmico no que concerne a realização de pesquisas e para a in dústria no que diz respeito à importância da Saúde Ocupacional dos seus colaboradores, beneficiando também o trabalhador, principalmente a ter o conhecimento sobre os seus direitos e leis que regem a sua jornada de trabalho.

Nesta perspectiva objetivou-se avaliar a percepção dos trabalhadores de soldagem em relação à exposição aos riscos de acidentes em seu local de trabalho.

\section{METODOLOGIA}

Tratou-se de um estudo descritivo e de natureza qualitativa, realizado em uma empresa de serviço de mecânica localizada no município de médio porte do Sudoeste da Bahia. A população deste estudo foi composta por 12 colaboradores do sexo masculino que trabalham na empresa, sendo a amostra formada por profissionais que atuam nos períodos matutino e vespertino no setor de soldagem, perfazendo o total de nove (o9) participantes. Três colaboradores não puderam participar da entrevista, onde o primeiro não se encontrava na empresa, o segundo se recusou a responder e o terceiro estava afastado.

Os entrevistados foram identificados pela letra $\mathrm{C}$ (colaborador) e numeração de 1 a $9\left(\mathrm{C}_{1}, \mathrm{C}_{2}, \mathrm{C}_{3}, \mathrm{C}_{4}\right.$, $\left.\mathrm{C}_{5}, \mathrm{C}_{6}, \mathrm{C}_{7}, \mathrm{C} 8, \mathrm{C} 9\right)$. Foram adotados os seguintes critérios de inclusão: colaboradores que trabalham exclusivamente no período matutino e vespertino, que aceitaram participar voluntariamente da pesquisa e assinaram o Termo de Consentimento Livre e Esclarecido e que estavam na escala de trabalho no dia da coleta de dados.

A pesquisa foi realizada no período de 01 a 15 de setembro de 2014 , com os profissionais de soldagem. Foram realizadas entrevistas gravadas com roteiro semi-estruturado. As entrevistas foram realizadas individualmente no local de trabalho com horário determinado junto aos profissionais mencionados. Eles foram orientados quanto ao objetivo da pesquisa e a pesquisadora ficou à disposição para esclarecer qualquer dúvida.

As entrevistas foram inicialmente transcritas para o programa Word/Starter 2010. Os dados foram analisados visando à identificação das categorias e unidades temáticas a partir da utilização do referencial de Bardin. As análises dos dados foram operacionalizadas a partir das seguintes questões: primeiramente foi realizada a leitura flutuante e aprofundada dos dados, grifando os relatos significativos, semelhantes e diferentes; recortes de fragmentos grifados; busca de categorias a partir das temáticas mencionadas no objetivo; elaboração de uma lista das respostas dos entrevistados por categorias; escolha dos questionários que possuem maior poder de síntese e abrangência, informações dentre os conteúdos das respostas para exemplificar as categorias emergentes.

A pesquisa foi autorizada pelo Comitê de Ética em Pesquisa (CEP) da instituição proponente, e está de acordo com a Resolução 466/12 do Conse- 
Iho Nacional de Saúde, sendo aprovada pelo protocolo $n^{\circ} 34732514.9 .0000 .5578$.

\section{RESULTADOS E DISCUSSÃO}

O trabalho do soldador é reconhecido como um trabalho que exige grande esforço e que representa risco ao profissional os quais podem afetar sua saúde e integridade física. $\mathrm{O}$ ambiente de trabalho geralmente comporta algum tipo de risco, seja ele químico, físico, biológico, mecânico (acidental) ou ergonômico. No trabalho relacionado à soldagem o soldador está exposto aos mais variados tipos de riscos que podem afetar sua saúde e integridade física. ${ }^{(2)}$

Para esse estudo participaram nove (09) trabaIhadores do setor de soldagem com idades variando entre 26 e 55 anos e tempo na profissão de 3 a 30 anos. O nível de escolaridade dos mesmos foram: ensino fundamental completo ( 3 participantes), ensino médio completo ( 3 ) e ensino médio incompleto (3). A jornada diária de trabalho é em geral de 8 horas divididas entre o turno matutino e vespertino.

A partir da análise das entrevistas os dados foram agrupados buscando um ponto em comum entre os discursos, surgindo assim 4 categorias de análise descritas a seguir.

$1^{\text {a }}$ CATEGORIA: O conhecimento dos soldadores acerca dos riscos em seu ambiente de trabalho.

Quando questionados sobre os riscos em seu ambiente de trabalho os entrevistados demonstraram algum conhecimento, segundo as falas descritas:

"Os fumos metálicos. Os gases que são emitidos pela solda que são tóxicos né?" (C1)

"Fumaça preta, produto químico, muita radiação." (C2)

"Só em termos de respiração, né? Respiratório por causa da fumaça que solta." ( $\left.C_{3}\right)$
"Risco de choque, químico e de queimadura." (C4)

"Riscos tem muitos, né? Queimadura, porque a gente trabalha com maçarico, choque na máquina, várias coisas... Tem de acidente também, porque a marreta escapole." ( $\left.C_{5}\right)$

Ainda que, de modo geral, os entrevistados apresentem algum conhecimento sobre os riscos presentes em seu ambiente de trabalho, identifica-se que não há um consenso ao listá-los, o que representa de certo modo pouco conhecimento a respeito do tema, o qual é baseado mais nos seus conhecimentos práticos do que nas informações que recebem da empresa.

Os fatores de risco variam de gravidade, porém, para todos eles o profissional deve adotar medidas de segurança para evitar acidentes e desenvolver um trabalho seguro. ${ }^{(8)}$

$2^{\text {a }}$ CATEGORIA: Fontes de informações para prevenção de acidentes.

Quando questionados sobre como a empresa oferece informações quanto a prevenção de acidentes e com qual frequência, vale destacar que apenas seis entrevistados afirmaram ter sidoorientados através de palestras, curso da CIPA (Comissão Interna de Prevenção de Acidentes) e distribuição de folders. Em relação à frequência, a maioria afirmou ser semestralmente e anualmente, o que pode ser verificado nas falas abaixo:

"Ofereceu o curso da CIPA. Oferece também os equipamentos de proteção, de alguma forma ajudando a gente." (CG)

"Com palestras e folhetos [...] Fazem isso de 6 em 6 meses." ( $\left.C_{7}\right)$

"Tive palestras, vídeos [...] Fazem anualmente." (C8)

Chamou a atenção durante a realização da entrevista o fato de um dosentrevistados afirmar que, 
apesar de receber orientações para prevenir acidentes, não faz o uso correto dos EPI's.

"A empresa faz palestras, distribui folhetos $e$ oferece equipamentos, mas a gente é descarado que não usa." ( $\left.C_{7}\right)$

Diante das respostas obtidas, mais uma vez nota-se que há uma divergência entre os participantes quanto ao modo que a informações são passadas e sua frequência. Assim sendo, como qualquer profissional, os soldadores devem conhecer todos os aspectos que contribuem para o surgimento das doenças ocupacionais e acidentes adotando medidas que estabeleçam um trabalho seguro. $O$ desinteresse em utilizar os EPI's induz a reflexão relacionada às formas de repasse de informações, se elas realmente existem e se são trabalhadas a sua importância.Para alguns trabalhadores os EPI's são desconfortáveis e dificultam o desenvolvimento do trabalho. Esse fato leva a crer que na realidade os colaboradores não reconhecem a gravidade dos riscos menosprezando sua segurança no trabalho.

Para evitar ou diminuir o número de acidentes no trabalho é necessário realizar um trabalho de educação mais efetivo através de palestras mais frequentes, treinamento prático, conscientização dos trabalhadores e fixação de placas no local de trabalho para todos os trabalhadores ficarem informados quanto aos riscos expostos e a importância da utilização dos EPI's, mas este trabalho não pode ser feito de modo compulsivo, não deve passado como se fosse uma obrigação à segurança, mas sim uma conscientização para ele mesmo.Assim o funcionário sentirá mais seguro com as informações e treinamento. ${ }^{(9)}$

A NR 18 que trata das condições de meio ambiente de trabalho na indústria da construção civil e contempla a função de soldador estabelece que o treinamento admissional deve ter carga horária mínima de 06 (seis) horas, ser ministrada em horário de trabalho, antes de o trabalhador iniciar suas atividades, constando de:

- Informações sobre as condições e meio ambiente de trabalho;
- Riscos inerentes a sua função;

- Uso adequado dos equipamentos de proteção individual; e,

- Informações sobre os equipamentos de proteção coletiva.

Segundo esta NR todos os empregados devem receber treinamento admissional e periódico, visando a garantir a execução de suas atividades com segurança. Ao final do treinamento, os empregados devem receber as ordens de serviço sobre segurança e medicina do trabalho e os EPI necessários às suas atividades e assinarem os termos de responsabilidade. ${ }^{(10)}$

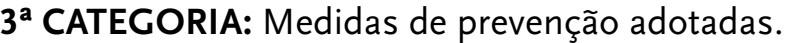

Em relação à prevenção de acidentes no trabalho oito colaboradores afirmaram fazer o uso do EPI's disponibilizados pela empresa, conforme as falas:

"Usando os materiais. Luva, máscara, máscara de solda" ( $\left.C_{1}\right)$

"A gente previne com as coisas que eles dão para a gente aqui. Proteção de ouvido, óculos, máscara." (C5).

"A gente usa o equipamento de... abafador de ouvido, máscara." (C9)

A ocupação de soldador faz parte de um enorme grupo de atividades laborativas que inevitavelmente submetem o trabalhador a exposição. Sendo assim, o trabalhador pode ter sua saúde e desempenho comprometidos a partir do momento em que não estão adequadamente protegidos ou sem qualquer proteção. ${ }^{(11)}$

Os EPI's possuem a função de proteger a integridade física e a saúde do trabalhador, reduzindo assim as lesões geradas pelos acidentes de trabalho. $\mathrm{O}$ uso desses equipamentos deverá ser feito caso não haja possibilidade de eliminar os riscos no ambiente de trabalho em que são realizadas as atividades.

Segundo a NR 6 - Equipamento de Proteção Individual - EPI, Cabe ao empregado quanto ao EPI: 
a. usar, utilizando-o apenas para a finalidade a que se destina;

b. responsabilizar-se pela guarda e conservação;

c. comunicar ao empregador qualquer alteração que o torne impróprio para uso; e,

d. cumprir as determinações do empregador sobre o uso adequado. ${ }^{(12)}$

$4^{\text {a }}$ CATEGORIA: Conduta adotada perante um acidente de trabalho.

Ao serem questionados a respeito das condutas adotadas imediatamente após a ocorrência dos acidentes houve respostas bem variadas quando comparadas as recomendações padronizadas.

"Procuraria um médico que é o mais certo, né?" (C1)

“Não sei. Não tenho nem ideia." (C2)

"Procurava o técnico de segurança." (Cو)

Ficou constatado que em caso de acidentes muitos dos colaboradores não sabem que atitude tomar por não saberem a quem se retratar. De acordo com a fala dos trabalhadores é necessário um profissional voltado à saúde do trabalhador. O enfermeiro tem uma visão holística, ou seja, consegue ver o indivíduo como um todo. Neste caso, é notório a necessidade de um profissional especial na área de saúde ocupacional. O enfermeiro do trabalho, por exemplo, é um profissional que deve estar constantemente na rotina da empresa para conseguir olhar o trabalhador de maneira holística conseguindo assim identificar os principais fatores que estão interferindo de maneira direta ou indireta no seu processo de trabalho ou no seu bem-estar.

O enfermeiro do trabalho é dotado de conhecimentos que the permite pôr em prática atividades de promoção da saúde, prevenção de acidentes e doenças relacionadas com o trabalho, além de capacitar os trabalhadores para situações de emergência. Estas atividades além de melhorar a eficácia da produção, reduzem o absenteísmo. ${ }^{(13)}$
Em caso de acidente deverá imediatamente ser informado por telefone ou pessoalmente ao Serviço Especializado em Segurança e Medicina do Trabalho (SESMT) e/ou a Comissão Interna de Prevenção de Acidentes (CIPA) da empresa para fins previdenciários e de investigação.

No Brasil, o acidente de trabalho ainda é considerado como um fenômeno decorrente de falhas humanas ou técnicas, traduzidas pelas expressões de ato inseguro e condição insegura. ${ }^{(5)}$

Na prática, pouca atenção é dispensada aos acidentes ocupacionais quando avaliamos sua alta frequência, sua significativa subnotificação e a necessidade de preveni-los em função das graves consequências que acometem os trabalhadores expostos a esses acidentes. ${ }^{(14)}$

A saúde dos trabalhadores bem como a segurança nos ambientes de trabalho é de suma importância, no entanto, algumas vezes, este fator é julgado como de menor seriedade, diante da busca por maior produtividade e menores custos em um ambiente globalizado. As condições em que se realizam as atividades profissionais têm consequências múltiplas para os trabalhadores afetando sua saúde, limitadas as possibilidades de evolução de suas competências e restringida sua capacidade laboral e de ampliação de sua experiência profissional. ${ }^{(15)}$

\section{CONCLUSÃO}

Os objetivos desta pesquisa foram alcançados conforme a apresentação dos resultados. Verificou-se que a percepção destes trabalhadores do ramo de soldagem em relação aos riscos que estão expostos é de baixa relevância. Ao mesmo tempo em que eles têm o conhecimento dos riscos que estão submetidos, eles não identificam qual EPI deverá usar e nem o dano que aquela exposição pode causar a sua saúde. Os achados indicados contribuíram para fortalecer a necessidade de uma atenção especial para a população estudada. Alguns dos resultados obtidos nesta pesquisa, em parte, tiveram 
a influência do nível de escolaridade, tendo em vista que mais de $50 \%$ dos entrevistados tem o nível fundamental incompleto ou completo, o que de certa maneira os caracteriza como sendo colaboradores que tem restrições em associar fator de risco, exposição ao fator e adoecimento. Há dificuldade também em compreender os riscos existentes no ambiente de trabalho e aderir o uso correto dos EPI's.

Contudo o presente estudo ratifica que a atenção a prevenção de acidentes e doenças no local de trabalho deve continuar a ser uma prioridade nas empresas. Desta forma, destaca-se a participação do Enfermeiro do Trabalho com foco na prática de ações voltadas para o conhecimento do trabalhador exposto a solda. Concludentemente, destaca-se o desenvolvimento de medidas educativas voltadas a suprir a falta de informação dos trabalhadores e condições de trabalho. Deste modo, salienta a fundamental participação do enfermeiro, uma vez que, o mesmo está capacitado para responder a todas as necessidades que existam.

\section{REFERENNCIAS}

1. Fernandes R de CP, Assunção AA, Carvalho FM. Mudanças nas formas de produção na indústria e a saúde dos trabalhadores, 2010. [acesso em: 15 jul 2014]. 15(Supl. 1):1563-1574. Disponível em: http://www.scielosp.org/pdf/csc/v15s1/O68.pdf.

2. Fuhr TA. Reconhecimento e avaliação dos riscos ambientais gerados nos processos de soldagem de uma empresa do segmento metal mecânico [monografia]. ljuí: Unijuí; 2012 [acesso em $\mathrm{O6}$ maio 2014]. Disponível em: http://bibliodigital. unijui.edu.br:8080/xmlui/bitstream/ handle/123456789/1259/Monografia\%2O Tiago\%2OA.\%2OF\%C3\%BChr\%2O\%2O Vers\%C3\%A3○\%2OFinal.pdf?sequence=1.

3. Matheus BP. Risco químico relacionado aos fumos de solda e poeira metálica. Revista rede de cuidados em saúde. 2009;3(3):1-10.

4. Marques PV, Modenesi PJ, Bracarense AQ. Soldagem: fundamentos e tecnologia. $3^{\mathrm{a}} \mathrm{ed}$. Belo Horizonte: Editora UFMG; 2009.
5. Goldman CF. Análise de acidentes de trabalho ocorridos na atividade da indústria metalúrgica e metal mecânica do estado do Rio Grande do Sul em 1996 e 1997 breve interligação sobre o trabalho do soldador [dissertação]. Porto Alegre: UFRGS; 2002 [acesso em 10 maio 2014]. Disponível em: http://www.producao. ufrgs.br/arquivos/publicacoes/claudio.pdf.

6. Lucena Neto, JG de. Um estudo da aplicação do conceito de risco na conscientização e conhecimento de estudantes de ensino técnico sobre riscos de segurança e saúde ocupacional em laboratório de soldagem [dissertação]. Natal: UFRN, 2007. Disponível em: http:// bdtd.bczm.ufrn.br/tde_arquivos/6/TDE-2O1OO4-26TO13737Z-2538/Publico/JoaoGLN.pdf. Acessado em: $\mathrm{O} 6$ de maio de 2014.

7. Gonçalves CG. Ministério do Trabalho. Portaria $n^{\circ}$ 3.214, de 08 de junho de 1978- NR O4, NR O5, NR O6, NR O9, NR 13. Diário Oficial da República Federativa do Brasil, Brasília; 2006.

8. Silva SA. Análise ergonômica do trabalho do soldador: contribuição para projetação ergonômica [dissertação]. Porto Alegre: UFRGS; 2003.

9. Baú G. Importância, conscientização e fatores intervenientes ao uso de EPIS na construção civil: estudo de caso [monografia]. ljuí: Unijuí; 2013 [acesso em 22 set. 2014]. Disponível em: http://bibliodigital.unijui.edu.br:8080/ xmlui/bitstream/handle/123456789/1584/ MONOGRAFIA_APROVADA_CORRIGIDA_ ENVIO_CRISTINA.pdf? sequence $=1$.

10. Brasil. Ministério do Trabalho e Emprego. NR 18 - Condições e Meio Ambiente de Trabalho na Indústria da Construção. Brasília: Ministério do Trabalho e Emprego; 2004 [acesso em $2 \mathrm{O}$ out. 2014]. Disponível em: http://portal.mte.gov.br/data/files/ FF8080812BE914E6O12BEFIFA6256BOO/nr_11. pdf.

11. Costa LG, Agnoletto RA, Catai RE, Romano CA, Matoski A. Análise do Ruído na ocupação de soldador em empresas de Curitiba e região Metropolitana. Anais do 30. Encontro Nacional de Engenharia de Produção; 2010 out. 1215 [acesso em: 18 jul. 2014]; São Carlos, São Paulo. Disponível em: http://www.abepro.org.br/ 
biblioteca/enegep2O1O_TN_STP_116_76O_16210. pdf.

12. Brasil. Ministério do Trabalho e Emprego. NR O6 - Equipamento de Proteção Individual. Brasília: Ministério do Trabalho e Emprego, 1996 [acesso em: 19 set. 2014]. Disponível em: http://portal.mte.gov.br/data/files/ FF8O8O812BE914E6O12BEF19CO9E2799/ nr_O7_ssst.pdf.

13. Oliveira AJE, Suzana MSA. Enfermagem em saúde ocupacional. Millenium. 2011 [acesso em:
25 out. 2014]; 41:115-122. Disponível em: http:// www.ipv.pt/millenium/Millenium41/8.pdf

14. Sarquis LMM, Felli VEA. Acidentes de trabalho com instrumentos perfurocortantes entre trabalhadores de enfermagem. Rev. Esc. Enferm. USP 2OO2;36(3):222-30.

15. Brasil. Ministério da Saúde. Política Nacional de Saúde do Trabalhador. Brasília: Editora do Ministério da Saúde; 2004. 